\title{
Werewere Liking, Médée. Les risques d'une réputation. Medea. I rischi d'una certa reputazione
}

\section{Veronica Cappellari}

\section{(2) OpenEdition}

12 Journals

\section{Edizione digitale}

URL: http://journals.openedition.org/studifrancesi/9696

DOI: $10.4000 /$ studifrancesi.9696

ISSN: 2421-5856

\section{Editore}

Rosenberg \& Sellier

\section{Edizione cartacea}

Data di pubblicazione: 1 décembre 2007

Paginazione: 703

ISSN: 0039-2944

\section{Notizia bibliografica digitale}

Veronica Cappellari, «Werewere Liking, Médée. Les risques d'une réputation. Medea. I rischi d'una certa reputazione», Studi Francesi [Online], 153 (LI | III) | 2007, online dal 30 novembre 2015, consultato il 09 janvier 2021. URL: http://journals.openedition.org/studifrancesi/9696 ; DOI: https://doi.org/10.4000/ studifrancesi.9696

Questo documento è stato generato automaticamente il 9 janvier 2021.

\section{(c) (1)}

Studi Francesi è distribuita con Licenza Creative Commons Attribuzione - Non commerciale - Non opere derivate 4.0 Internazionale. 


\title{
Werewere Liking, Médée. Les risques d'une réputation. Medea. I rischi d'una certa reputazione
}

\author{
Veronica Cappellari
}

\section{NOTIZIA}

WEREWERE LIKING, Médée. Les risques d'une réputation. Medea. I rischi d'una certa reputazione, introduzione e cura di Anna Paola MOSSETTO, traduzione e nota di Nataša RASCHI, postfazione di Sara TAGLIACOZzo, Torino, Edizioni Libreria Stampatori, 2007, pp. 142.

1 Ispiratrice di Sofocle e di Euripide, cantata da Ennio e da Seneca e in età moderna da Pierre Corneille e Jean Anouilh, fino a ispirare l'omonimo film di Pier Paolo Pasolini nel 1970, Medea, figlia del re della Colchide, nipote del Sole, sacerdotessa di Ecate, maga innamorata e poi tradita, che diviene, per fatalità, infanticida, è ora oggetto di una interessante e singolare rilettura mitica in chiave africana. Opera di Werewere Liking, scrittrice, drammaturga, musicista e regista di origine camerunese, fondatrice del Village Ki-Yi, "il villaggio del sapere ultimo", un centro residenziale di ricerca e produzione teatrale con sede ad Abidjan, Médée. Les risques d'une réputation, è stata presentata in prima mondiale nel 2005 al Teatro Baretti di Torino dalla Compagnia multietnica AlmaTeatro.

2 Sulla scia del romanzo di Christa Wolf, che nel 1996 ne riscrisse il mito sciogliendo l'eroina dalle sue sanguinose colpe e dalla violenza irrazionale di cui la fece portatrice Euripide, Werewere Liking, con quest'opera - l'opera viene qui pubblicata per la prima volta in versione originale francese con traduzione a fronte - rilegge il mito della straniera dalle arti e dai poteri occulti in chiave attuale e contemporanea, affrancandola dai suoi poteri inquietanti, vendicativi e talora spietati. Non più maga ammaliatrice, madre infanticida o sposa tradita che, accecata dalla gelosia, sacrifica i suoi stessi figli pur di vendicarsi del suo giovane eroe, Giasone, quando questi le 
preferisce una più giovane e meno esotica moglie greca. Nella versione della Liking, l'omicidio dei fanciulli è presentato come una calunnia che si ripercuote sulla reputazione di Medea, un intrigo insidioso ordito dai Corinzi, i veri responsabili dell'infanticidio, che sfruttano la sua condizione di straniera per manifestarle il loro sospetto e la loro diffidenza. Questa figura femminile fatale non incarna qui soltanto l'immagine della straniera, della barbara che difficilmente si adatta ai costumi greci, e che, avvolta nel mistero, altera e indebolisce la stabilità di una comunità, chiusa e gelosa dei propri confini; accanto al tema dell'intolleranza, si sviluppa infatti anche quello dello scontro fra matriarcato al tramonto e sistema patriarcale ormai dominante. Fedele ai propri ideali, Medea non si inchina alla legge del più forte: esige la fedeltà e la dignità matrimoniale, come pure il rispetto da parte di una società - sia essa di stampo occidentale o africano, antico o moderno -, che si presenta talora ipocrita, intransigente e discriminante o semplicemente schiava di antichi e superati stereotipi e pregiudizi.

3 Come sottolinea nella sua postfazione l'antropologa Sara Tagliacozzo, la riscrittura drammatica di Medea fatta dalla Liking presenta una triplice raffigurazione dell'eroina (Medea Fonte - la pasionaria; Medea Affluente - la straniera; Medea Fiume - la sacerdotessa), inserita in quella specificità molteplice, plurima e complessa del mondo africano che non consente di «mettere in scena qualunque simbolo di un'africanità essenziale» (p. 133). Il volume si avvale, inoltre, della suggestiva e pregevole introduzione di Anna Paola Mossetto, nella quale la studiosa, oltre a sottolineare l'infinita possibilità di risemantizzazione del mito, incarnazione emblematica dell'immortalità, rileva un'altra notevole "sfida", quella affrontata dalla traduttrice Nataša Raschi, che con acribia ha saputo restituire al pubblico italiano la spiritualità della Medea di Werewere Liking, una pièce-poème, come la definisce la stessa Raschi nella sua «Nota» sulla traduzione, accostabile, per l'alternarsi di rime, assonanze e ritmi musicali, a un pezzo classico.

Il libro si chiude con un'intervista rilasciata dalla scrittrice a Nataša Raschi nel gennaio 2005 a Torino, nella quale rivela la fonte delle proprie ispirazioni e il motivo delle proprie scelte a proposito del soggetto, nonché la propria riflessione sull'importante ruolo che l'arte teatrale gioca all'interno della nostra società. Attraverso la rilettura del mito occidentale, la drammaturga fa del proprio teatro uno strumento di ricerca e di conoscenza di un ideale luogo di incontro delle differenti culture, suscitando, nel contempo, emozioni e desiderio di allargare i confini della propria riflessione. 